\title{
PROCESSOS DE SOCIALIZAÇÃO NO QUILOMBO TOCA DE SANTA CRUZ DO MUNICÍPIO DE PAULO LOPES (SC): "EU NÃO SOU DA IGREJA, EU SOU DO TERREIRO"
}

Gisely Pereira Botega*

Patrícia de Moraes Lima**

\begin{abstract}
Resumo
Este artigo apresenta um recorte de uma pesquisa de doutorado em Educação ainda em andamento. Ele tem por objetivo conhecer e apresentar processos de socialização entre mulheres e crianças moradoras da comunidade quilombola Toca de Santa Cruz, localizada no município de Paulo Lopes, em Santa Catarina (SC). Além disso, buscou-se, a partir dele, dar visibilidade para o reconhecimento de tal território como quilombo a partir de aspectos etno-políticos. Os dados foram coletados a partir de uma abordagem etnográfica. Neste texto, apresentamos registros do diário de campo produzido a partir das cerimônias religiosas em um terreiro de Umbanda frequentado pelas mulheres e pelas crianças quilombolas. Os dados revelam que os processos de socialização potencializam a vida e os modos de resistências à opressão, às violências, ao branqueamento, ao racismo e à invisibilidade dos sujeitos da Toca.
\end{abstract}

Palavras-chave: Quilombo. Processos de socialização. Terreiro.

\footnotetext{
* Doutoranda do Programa de Pós-Graduação em Educação da Universidade Federal de Santa Catarina (UFSC). Integrante do Núcleo de Estudos e Pesquisas sobre Violências (NUVIC.E-mail: gibotega@gmail.com.

** Pós-doutora pela Faculdade de Psicologia e Ciências da Educação na Universidade do Porto, em Portugal. Professora da área de Educação e Infância do Curso de Pedagogia e do Programa de Pós Graduação em Educação da Universidade Federal de Santa Catarina (UFSC) e coordenadora do Núcleo de Estudos e Pesquisas sobre as Violências (NUVIC. E-mail: patricia.demoraeslima@gmail.com.
} 


\section{Introdução}

Este artigo apresenta fragmentos de uma pesquisa de doutorado, ainda em andamento, vinculada ao Programa de Pós-Graduação em Educação da Universidade Federal de Santa Catarina (UFSC), ${ }^{1}$ que trata sobre os processos de socialização de mulheres e de crianças no quilombo Toca de Santa Cruz localizado no município de Paulo Lopes, em Santa Catarina (SC). Os processos de socialização são transversalizados por processos outros, como oralidade, tradição, ancestralidade, relações de gênero, feminilidade, raça, pertencimento, movimentos da diáspora, de inventividade e resistências, os quais dizem como estas mulheres vão se constituindo como negras e quilombolas na potência política, afetiva e estética nos encontros com a infância quilombola.

A partir da etnografia ${ }^{2}$ acessamos, nessa cotidianidade, processos de socialização, no espaço do quilombo, entre mulheres e crianças que potencializam a vida e os modos de resistência à opressão, às violências, ao branqueamento, ao racismo, à discriminação e à invisibilidade desses sujeitos da Toca. Para Fonseca (1999, p. 10),

[...] a etnografia é uma ciência, por excelência calcada no concreto. O ponto de partida desse método é a interação entre o pesquisador e seus objetos de estudo, nativos em carne e osso. É, de certa forma, o protótipo do qualitativo. E, melhor ainda, com sua ênfase no cotidiano e no subjetivo, parece uma técnica ao alcance de praticamente todo mundo, uma técnica investigativa, enfim, inteligível para combater os males da quantificação.

Elegemos o recorte etnográfico denominado "eu não sou da igreja, eu sou do terreiro" para dar visibilidade aos processos de socialização entre mulheres e crianças quilombolas no terreiro de Umbanda e, com isso, pensarmos sobre essas práticas sociais no interior da vida cotidiana do quilombo. Partimos do argumento de que essas práticas de socialização poderão ser analisadas a partir das relações intrageracionais entre adultos
1 A referida pesquisa de doutorado vem sendo realizada sob a orientação da Prof. ${ }^{a}$ Dr. ${ }^{a}$ Ana Maria Borges de Sousa e conta com bolsa UNIEDU/ FUMDES.

2 Uma das ferramentas fundamentais deste método diz respeito ao insubstituível diário de campo que o pesquisador utiliza para fazer os registros dos acontecimentos do campo. A partir deste método, é possível tecer problematizações e conclusões quanto aos nativos e o terreno de pesquisa: seus modos de vida, suas formas de organização social, seus valores familiares, suas crenças religiosas, suas atitudes políticas, etc. Para isso, o pesquisador etnógrafo percorre um processo de estranhamento, de esquematização dos dados empíricos, de desconstrução de estereótipos, de comparação com exemplos tirados de literaturas e de sistematização do material. 
3 As informações estão disponíveis nos sites: <http:// www.paulolopes.sc.gov. $\mathrm{br} / \mathrm{cms} / \mathrm{pagina} / \mathrm{ver} / \mathrm{cod}$ MapaItem/58298> E <http:// cidades.ibge.gov.br/xtras/perfil. php?lang $=\&$ codmun $=421230$ \&search=santa-catarina $\mid$ paulolopes> (mulheres) e crianças, da interdependência entre esses sujeitos e dos processos que incidem sobre a ancestralidade nessa comunidade.

Neste artigo, buscamos dar visibilidade ao processo de reconhecimento da comunidade Toca de Santa Cruz como quilombola e articular uma cartografia a partir da genealogia desse território, tomado aqui a partir de suas linhas e relevos geográficos e seus aspectos históricos, sociais e etno-políticos. Enfatizamos a ideia da cartografia das paisagens psicossociais do quilombo a partir de Rolnik (2014) em contraposição à ideia de uma paisagem fixa. Os aspectos da socialização entre mulheres e crianças, no espaço da comunidade Toca de Santa Cruz e fora dela são aqui explorados principalmente a partir da circulação nos terreiros de Umbanda.

\section{Genealogia da Toca de Santa Cruz: aspectos geo- políticos}

O município de Paulo Lopes tem colonização açoriana. Segundo consta no site da prefeitura municipal (MUNICÍPIO DE PAULO LOPES, [2016]) e nos registros do Instituto Brasileiro de Geografia e Estatística (IBGE, [2016]), ${ }^{3}$ o processo de ocupação do município ocorreu a partir do século XVII, quando algumas famílias açorianas, sob o comando do coronel da força militar portuguesa Paulo Lopes Falcão, construíram suas casas e desbravaram e cultivaram a região com o apoio de índios carijós, que, em pequeno número, viviam no local, e de escravos africanos. Os que ali viviam dedicavam-se, principalmente, à fabricação de farinha e ao cultivo de milho.

Em livro escrito por Manoel Venâncio Machado (1993, p. 15), professor da rede municipal de Paulo Lopes no passado, destaca-se que "a população de Paulo Lopes é constituída de uma só origem: a açoriana”. $\mathrm{O}$ autor relata que as terras que hoje pertencem ao município foram divididas em sesmarias e entregues aos portugueses. Dentre estas, destacou-se a parte dada ao capitão Manuel da Costa, conhecido como 
Coronel Pindá. Ele, junto com outros moradores e com seus escravos, deu forte impulso às terras que lhe foram entregues, construindo engenhos de farinha e de açúcar. Com a chegada de agricultores e com a expansão "ergueram-se por todo o território paulolopense moradias feitas de pau a pique, tudo isto com o auxílio do braço forte e corajoso do negro escravo" (MACHADO, 1993, p. 33). Observamos, portanto, que, apesar da colonização açoriana, há registros da ocupação e da presença dos negros no passado e no presente, especialmente concentrada na comunidade Toca de Santa Cruz.

A comunidade de Santa Cruz, conhecida popularmente como Toca, lugar em que vivem os(as) negros(as) do município, vem passando por um processo de reconhecimento quilombola que vem se intensificando desde o ano de 2007. Vale salientar que foi sancionada uma lei municipal de reconhecimento da Associação Comunitária Quilombolas da Toca de Santa Cruz, a Lei no 1.319, de 3 de março de 2009 (ESTADO DE SANTA CATARINA, 2009). É possível verificar no link da Fundação Palmares o registro da comunidade. ${ }^{4}$

Nesse processo de reconhecimento e de demarcação do quilombo, houve a contribuição de alguns profissionais do Instituto Federal de Santa Catarina (IFSC), a partir de um projeto de extensão do campus de Florianópolis (SC), o "Poloexpaulolopes", no ano de 2010, vinculado ao programa de formação coordenado por Silvana Maria Frigotto. Além do IFSC, voluntários da prefeitura municipal de Paulo Lopes, da OAB cidadã, da ONG Nova Acrópole e da Associação Capoeira na Escola participaram do que denominaram como ação social na comunidade. Registramos também a contribuição do Movimento Negro Unificado (MNU), que atua no debate permanente com os moradores(as), especialmente em ações através da associação quilombola, há mais de dez anos. Destaca-se que, desde março de 2015, vem sendo produzido o relatório antropológico de identificação e de reconhecimento territorial através do trabalho realizado por um antropólogo, um historiador e uma ambientalista, todos contratados pelo Instituto Nacional de Colonização e Reforma
4 Informações sobre o processo podem ser verificadas em: <http://www.palmares.gov. br/?page_id=88\#>. Acesso em 10 jun. 2016. 
Agrária (INCRA). Na fase atual, busca-se a demarcação das terras junto aos(às) moradores(as) a partir de encontros com discussões coletivas para, posteriormente, o INCRA produzir o Relatório Técnico de Identificação e delimitação (RTID).

5 Informação contida nos diários de campo dos dias 20 de março de 2016 e 21 de maio de 2016.

6 Dado obtido em dezembro de 2015 na Secretaria Municipal de Saúde através do cadastro de uma agente comunitária da saúde da família vinculada ao programa Estratégia de Saúde da Família (ESF) e que atua na comunidade há 10 anos.

7 Este dado foi levantado em outras pesquisas: Botega (2002; 2006).

8 Dados apresentados nas pesquisas de Botega (2006) e de Botega e Tramonte (2015). soube-se que os(as) negros(as) vivem naquelas terras há mais de cem anos e que são descendentes de três famílias com os seguintes sobrenomes: Marcelino, Felipe e Jesus. Outro dado relevante apresentado é que os moradores(as) brancos(as) da comunidade quilombola possuem documentação de suas terras, ao contrário dos moradores(as) negros(as). Destacou-se a preocupação de as terras das famílias negras estarem ficando cada vez mais reduzidas, não se tendo espaço para áreas de lazer e de reuniões na comunidade. A partir de um mapa realizado através da memória dos moradores(as) negros(as), os profissionais contratados pelo INCRA vêm buscando construir junto à comunidade a demarcação do seu território no presente. Questões como, por exemplo, fontes de água, local para área coletiva de lazer, espaço para moradia dos(as) futuros(as) descendentes, melhoria na habitação e acesso à rede de saneamento e a água tratada vêm sendo problematizadas entre tais profissionais e os(as) moradores(as).

A comunidade é constituída por um número de aproximadamente cento e cinquenta ${ }^{6}$ moradores(as) quilombolas, de diferentes gerações, sendo a maioria de baixa renda. O local é marcado pela liderança das mulheres, responsáveis pela educação e pelo cuidado das crianças. ${ }^{7}$ Além das famílias quilombolas, vê-se, cada vez mais, um número expressivo de famílias brancas habitarem tal território, processo que ocorre desde a década de $1970 .{ }^{8}$ Em pesquisa anterior, Botega (2006), a partir das narrativas de avós negras e brancas, ou seja, das moradoras negras e brancas mais antigas, registrou que, entre os anos de 1970 e 1980, a comunidade Toca de Santa Cruz começou a ser habitada por algumas famílias brancas que vieram de outros municípios em busca de terras para plantar, com o objetivo de trabalharem na agricultura. A escolha por essa comunidade ocorreu, sobretudo, porque a 
terra era boa e barata para a agricultura, uma vez que, com pouco dinheiro, era possível comprar muitas terras, e por incentivo de alguns parentes que já moravam no município. A seguir, apresentamos uma imagem aérea da comunidade:

Figura 1 - Vista área da comunidade Toca de Santa Cruz

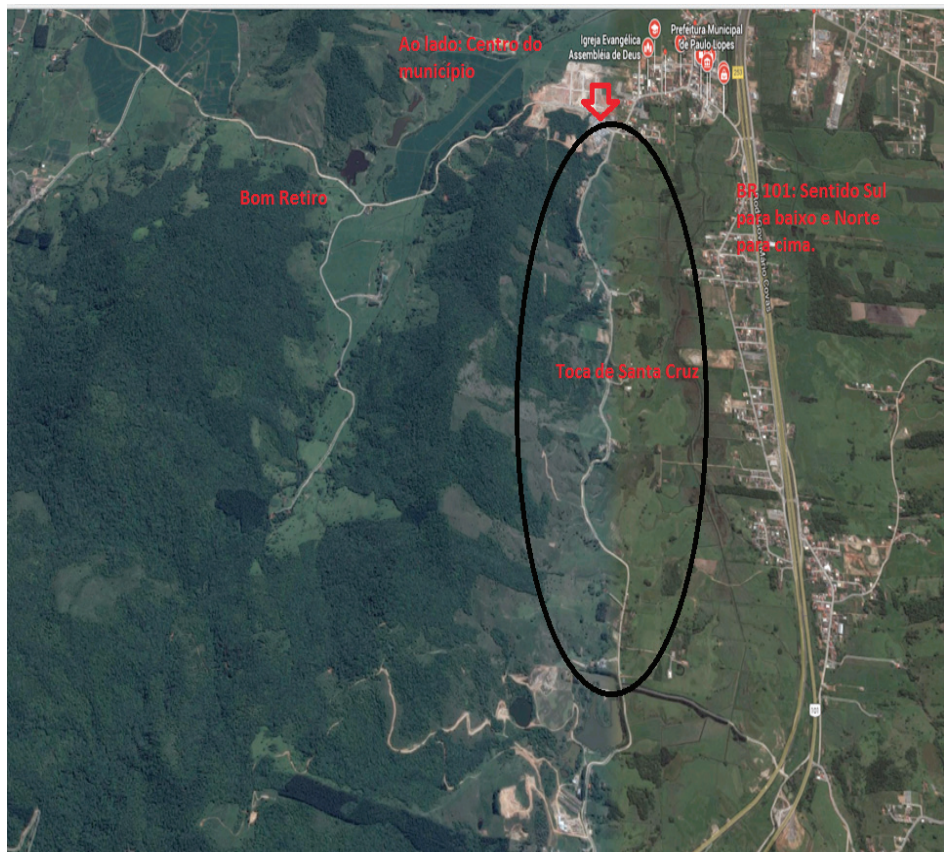

Fonte: GOOGLE. Google Earth. Rua Manoel Felipe, Paulo Lopes (SC).

Como se pode ver, a comunidade quilombola localizase próximo ao centro do município. A seta vermelha indica o local onde fica o cemitério municipal, localizando-se a entrada na comunidade ao lado deste. Essa rua de entrada, que corta a comunidade, chama-se Manoel Felipe de Jesus e ainda não é calçada. Ao lado direito e um pouco acima da seta, podemos localizar o centro do município, onde fica seu centro administrativo (prefeitura) e diversos comércios. A seguir, apresentamos mais duas imagens: na primeira, localiza-se a entrada da comunidade e, na segunda, temos uma imagem do interior do quilombo: 
Figura 2 - Vista da entrada da comunidade Toca de Santa Cruz

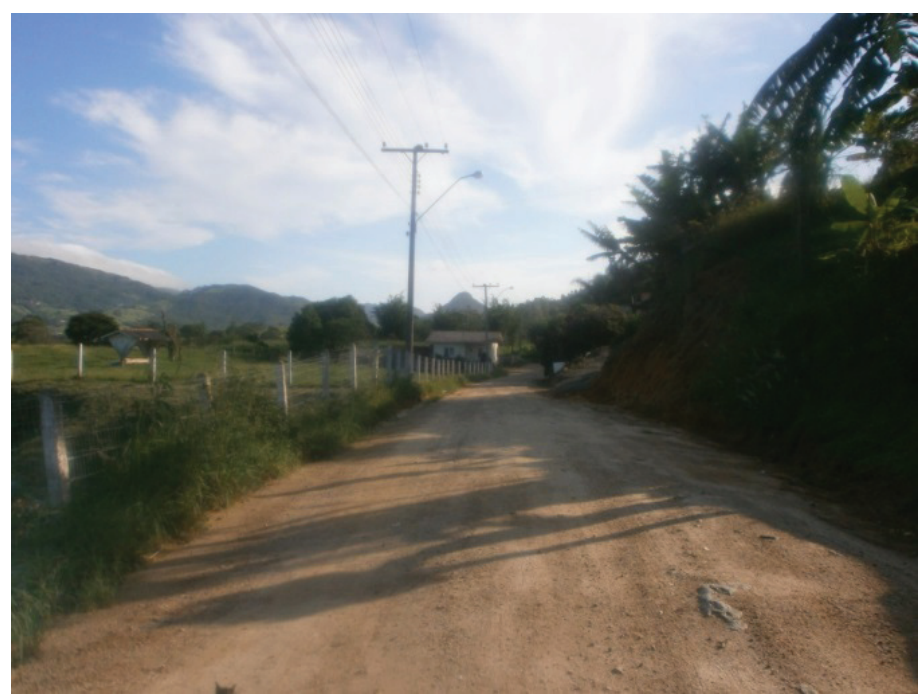

Fonte: Acervo pessoal das autoras

Figura 3 - Percorrendo a Toca de Santa Cruz

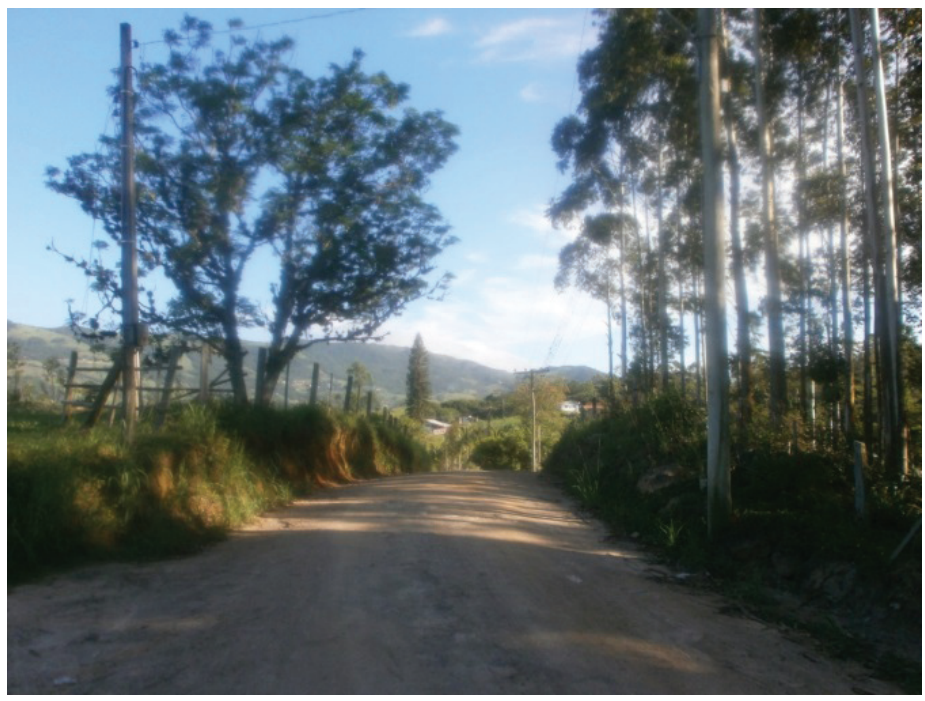

Fonte: Acervo pessoal das autoras

Percebemos o quanto este trabalho, que envolve e une a genealogia e geografia da comunidade, é fundamental para potencializar os processos identitários quilombolas. As questões relacionadas ao passado da comunidade, identificadas 
através da memória dos(as) habitantes mais velhos(as), e os processos de socialização do presente são tomados como fortes elementos de demarcação de direitos étnicos. Não podemos esquecer que é a palavra o principal "documento" destes sujeitos; é através dela, suscitada pela memória e pela ancestralidade, que os(as) moradores(as) nos dão a honra de acessar histórias desconhecidas e desconsideradas pelos registros oficiais. Pelos quilombolas, expandimos nossas verdades, que teimam em se amparar nos documentos oficiais e no silenciamento sobre a ancestralidade desse grupo.

\section{O quilombo como cartografia da resistência}

Leite (2008) considera que, no século XXI, o quilombo ressurge como uma das principais formas de denunciar a ideologia do embranquecimento e da exclusão dos(as) negros(as) do projeto de modernização do país. Nos anos 1970 e 1980, o quilombo foi levado à Assembléia Nacional Constituinte (1988) com apoio dos militantes do Movimento Negro Unificado (MNU) e de parlamentares como Abdias do Nascimento e Benedita da Silva (primeira senadora negra), que se ocuparam com a dimensão jurídica; com isso, deu-se início ao debate do artigo $68^{\circ}$ da Constituição, que diz que "aos remanescentes das comunidades dos quilombos que estejam ocupando suas terras é reconhecida a propriedade definitiva, devendo o Estado emitir-lhes os títulos respectivos" (BRASIL, 1988). Esse artigo, inscrito nas Disposições Constitucionais Transitórias, enfrentou grandes opositores na Câmara Federal e no Senado, levando quase 20 anos para ser regulamentado. Neste momento, as terras dos quilombos são consideradas parte do patrimônio cultural dos grupos que as ocupam e, como tal, devem ser protegidas pelo Estado. Segundo Leite (2008, p. 969),

As reivindicações de organizações de movimentos negros e setores progressistas, como parte da própria reflexão sobre o Centenário da Abolição da Escravidão no País, levadas à Assembleia Constituinte 
de 1988, favoreceram a aprovação de dispositivos constitucionais concebidos como compensação e/ou reparação à opressão histórica sofrida.

Para O'Dwyer (2009), a partir da Constituição de 1988, o termo "quilombo" adquiriu nova significação ao ser inscrito no artigo $68^{\circ}$ do Ato das Disposições Constitucionais Transitórias (ADCT); antes de uso quase praticamente apenas por historiadores ao referir-se ao nosso passado como nação, ele então passa a conferir direitos territoriais aos remanescentes de quilombos que estejam ocupando suas terras, sendo-lhes garantida a titulação definitiva pelo Estado brasileiro.

Para Tramonte (2009) os quilombos, no imaginário brasileiro, muitas vezes são referenciados como agrupamentos de africanos fugitivos, que tinham como objetivo reproduzir os modos de vidas de sua terra de origem. Não é de se surpreender que, quando o assunto é quilombo, lembramonos dos conhecimentos sobre o quilombo de Palmares, imagem da luta e da resistência dos(as) negros(as) e de outros excluídos da época, sobre as figuras de Zumbi e de Ganga Zumba, referências de luta pela terra, e sobre o movimento rebelde que se opôs à administração colonial por quase dois séculos. Assim, quando se trata de imaginário, há desafios para a (des)construção da noção de quilombo na contemporaneidade, a começar pela própria linguagem que se refere ao quilombo e a suas representações, tais como as expressões "remanescentes de quilombo", "terra de pretos" ou "terra de quilombo", "comunidades negras rurais", "terras ocupadas por descendentes de escravos”, etc. São inúmeras as definições de quilombo ao longo da história, conforme aponta Moura (2004), e elas são baseadas em fatos que marcaram a alma do povo brasileiro, mas nos falam também de direito à terra e à sobrevivência enquanto povo e cultura específicos. Afinal, nossa terra foi habitada por populações negras que se estabeleceram em territórios, cultivando-os e trazendo benefícios econômicos, onde criaram família e raízes, pois ali encontraram paz e refúgio; neles, fizeram história. Por isso, atualmente, eles reivindicam seu direito a permanecer nesse espaço eivado de ancestralidade. 
Para Tramonte (2009), pensar no quilombo contemporâneo é tratar do direito à terra, dos espaços de lutas, de resistência e de lugares de ancestralidade, onde se propagam saberes, processos de trocas e ocorre socialização, ao se considerar os conhecimentos do grupo como saberes tradicionais (religiosidade, saúde popular/benzedeiras, curandeiras, festividades, etc.).

Vale ressaltar que, em 2003, foi assinado o Decreto no 4.887 (BRASIL, 2003), que trata da identificação, do reconhecimento, da delimitação, da demarcação e da titulação das terras ocupadas pelos remanescentes das comunidades de quilombos, conforme o artigo $68^{\circ}$ das Disposições Constitucionais Transitórias, que garante a posse da terra e o acesso a serviços como saúde, educação, moradia e saneamento básico. A legislação apresenta uma novidade: ressalta os direitos étnicos e territoriais e considera como remanescentes de comunidades quilombolas, conforme seu artigo 20, "os grupos étnico-raciais, segundo critérios de autoatribuição, com trajetória histórica própria, dotados de relações territoriais específicas, com presunção de ancestralidade negra relacionada com a resistência à opressão histórica sofrida" (BRASIL, 2003, p. 01).

Para O'Dwyer (2008), o termo quilombo, na contemporaneidade, refere-se a resíduos ou resquícios arqueológicos de ocupação temporal ou comprovação biológica. Não se trata de grupos isolados ou homogêneos, pois eles nem sempre foram constituídos por movimentos de rebelados. $\mathrm{Na}$ realidade, os quilombos consistem em grupos que constroem práticas cotidianas de resistência para assegurar a manutenção e a reprodução de seus modos característicos de vida e a consolidação de um território próprio. No que tange à ocupação, à territorialidade desses grupos, estas não acontecem a partir de lotes individuais, mas do predomínio do uso comum e das diversas formas de utilização desses territórios. Toma-se por base, para tanto, laços de parentesco e de vizinhança, assentados em relações de solidariedade e de reciprocidade. Assim, segundo O’Dwyer (2008, p. 10), 
"A identidade desses grupos também não se define pelo tamanho e número de seus membros, mas pela experiência vivida e as versões compartilhadas de sua trajetória comum e da continuidade enquanto grupo".

Nesse sentido, a cartografia do quilombo representa processos de resistência, na medida em que paisagens psicossociais são cartografáveis. Diferentemente do mapa, que representa um todo estático, a cartografia acompanha os movimentos de transformações e se faz, ao mesmo tempo, no desmantelamento de certos mundos por sua perda de sentido e pela formação de outros mundos, que se criam para expressar afetos contemporâneos, em relação aos quais os universos vigentes tornaram-se obsoletos. Uma cartografia da resistência permite "mergulhar na geografia dos afetos e ao mesmo tempo criar pontes para fazer sua travessia: pontes de linguagem" (ROLNIK, 2014,p. 23 e 66). É como se a cartografia deslizasse por territórios habitados socialmente e materialmente, por linhas subjetivas que simulam e experimentam roteiros de circulação no mundo, onde sujeitos, assim como objetos, são desterritorializados e reterritorializados por uma memória, uma biografia que os constitui.

O mapeamento cartográfico dos quilombos representa linhas e relevos de territórios que dizem do pertencimento étnico-racial de inúmeras famílias, homens, mulheres e crianças. Os territórios, assim, demarcam paisagens psicossociais, pois se constituem pela dimensão da memória, do parentesco, da oralidade e da ancestralidade. Os processos de socialização, nos quilombos, carregam os traços de uma geo-grafia e de uma ge-nealogia dos que ali habitam.

\section{As mulheres e as crianças e seus processos de socialização no quilombo}

Para tratarmos sobre os processos de socialização entre mulheres e crianças no quilombo Toca de Santa Cruz, buscaremos dar visibilidade a um dos principais grupos familiares quilombola que compõem esta pesquisa, o de Natalina e seus familiares. Nesse grupo, a figura de Natalina 
foi fundamental, pois permitiu nossa circulação nas diferentes gerações de seu grupo familiar. A escolha pela aproximação se deu especialmente por ela ser líder na associação quilombola. Outro motivo que nos levou até ela foi geográfico, pois sua casa fica em um ponto central da comunidade; ao redor dela, há outras casas de famílias quilombolas, e, na frente, os moradores quilombolas se reúnem para jogar, brincar, ouvir música, organizar festas e conversar. Como não existem ambientes de lazer na comunidade, como praças e clubes, os moradores acabam criando espaços de encontro que garantam minimamente o lazer e interação.

Natalina é praticante da religião Umbanda. ${ }^{9}$ Ela tem 64 anos e é casada há 50 anos com Nilzo, com quem tem 8 filhos biológicos e 8 de criação, os quais lhe deram 29 netos e 3 bisnetos. Destes, pudemos ter mais contato com os filhos biológicos, já que os filhos de criação são, em sua maioria, moradores da cidade de Florianópolis (SC), com exceção de Andressa e Andriano, ainda crianças e netos de Natalina, porém considerados por ela filhos de criação: "fui eu quem criei, então são meus". ${ }^{10}$ No genograma abaixo, é possível visualizar a composição desse grupo familiar e suas gerações:

Figura 4 - Genograma: composição familiar

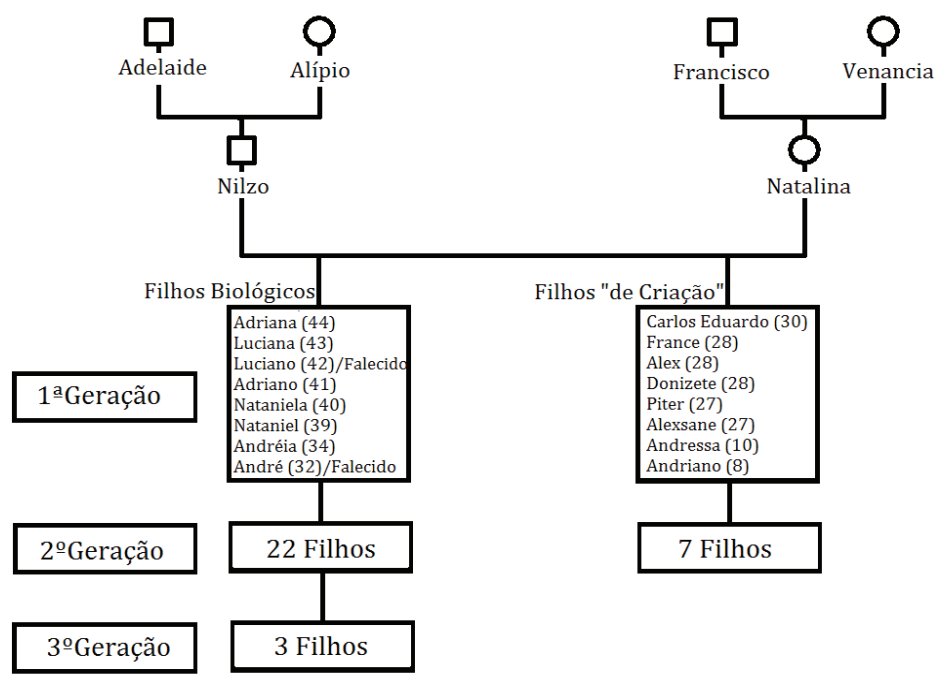

9A umbandaéuma religião afrobrasileira que, segundo Ortiz (1978, p. 69), "fundamenta-se no culto dos espíritos e é pela manifestação destes, no corpo do adepto, que ela funciona e faz viver suas entidades". Uma das características da umbanda é seu sincretismo a partir de matrizes negras, como o candomblé, matrizes ocidentais como o catolicismo e o kardecismo, juntando ainda elemento da cultura indígena. A Lei no 12.644/12 instituiu o dia nacional da umbanda no dia 15 de novembro.

10 Informação contida no Diário de Campo de 24 de setembro de 2016.

Fonte: Elaborado pelas autoras 
A partir da convivência com esse grupo familiar, observamos a participação e a presença das crianças em distintos momentos vividos com as mulheres no espaço do quilombo e fora dele, como em festas, reuniões, manifestações, cerimônias religiosas, etc. Era muito comum chegarmos à Toca e encontrarmos as crianças pela rua brincando, correndo, dançando, andando de bicicleta, jogando futebol ou bola de gude, acessando jogos em aparelhos celulares, entre outras atividades. A rua é o lugar dos mais inimagináveis acontecimentos. É lugar de encontro. Outro aspecto que nos chamou atenção na relação entre mulheres e crianças diz respeito aos penteados, especialmente à produção das tranças. É comum mulheres fazerem tranças nos cabelos das crianças - nas meninas, especialmente; para além de uma prática que preserva a estética e a afirmação étnica, o penteado, nos cabelos das crianças, apresenta-se como uma prática de ancestralidade:

11 Informação contida no diário de campo do dia 24 de abril de 2016.
Era domingo, por volta das 10 horas da manhã, estava um dia de sol e calor, decidimos ir até a casa de Natalina, pelo caminho encontramos crianças a brincar pela rua. Chegando lá fomos recebidas por ela com entusiasmo, ao entrarmos vimos que na sala estavam sua filha Nataniela sentada no sofá fazendo tranças nas meninas: Ana Francisca (12 anos), Nataniele (15 anos) e Andressa (10 anos). Natalina já estava com tranças nos cabelos e ela comenta: aqui todo mundo vai aprendendo a fazer tranças. Perguntamos quem tinha lhe ensinado a fazer tranças. Ela diz: isso já vem passando de geração em geração. ${ }^{11}$

As tranças eram feitas, refeitas e ensinadas. No gesto de trançar, preservam-se traços da ancestralidade de um grupo. Das mais diversas formas e jeitos que se possa imaginar, a trança é como um adereço ao processo de estetização das mulheres e das crianças quilombolas. Algumas tranças são feitas manualmente e outras são aplicadas e ficam nos cabelos por um determinado tempo - estas geralmente são compradas pelas mulheres em Florianópolis. Vê-se nisso um processo de consumo e de aproximação com um mercado que não existe em Paulo Lopes. 
Como reflete Paula (2014), é na relação com os(as) moradores(as) do quilombo que a criança negra potencializa seus laços de pertencimento racial ligados a uma ancestralidade comum, mobilizando uma estética positiva de si. Desse modo, a infância quilombola é um acontecer constante e diário, são as crianças capazes de reinventar a rotina, os ritmos do dia a dia no quilombo e a si próprias. São crianças que circulam por todos os espaços do quilombo e fora dele, em todos os momentos, pois estão constantemente na rua, na vizinhança, no rio que desliza pela mata e no campo de futebol, onde fazem brincadeiras, por vezes inclusive sem a supervisão e o controle dos adultos.

\section{"Eu não sou da igreja, eu sou do terreiro": as mulheres e as crianças quilombolas no espaço de socialização do terreiro}

Um dos convites mais surpreendentes que recebemos, durante o período que estivemos no terreno, foi, sem dúvida, o para irmos ao terreiro de Umbanda na grande Florianópolis, pois desconhecíamos que algumas mulheres quilombolas da Toca de Santa Cruz deslocavam-se até a região, juntamente das crianças, para frequentá-lo. Nesse espaço, percebemos processos de socialização e de reconhecimento da matriz religiosa africana. Natalina nos narrou que costuma frequentar terreiros na região da grande Florianópolis, especialmente nas regiões centrais e do sul da ilha. Em janeiro de 2016, Natalina recebeu convite do pai de santo do terreiro Centro Espírita Choupana de Obaluaê, localizado no bairro Tapera e, para nossa surpresa, convidou-nos para irmos junto dela e dos familiares. Lá, tivemos a oportunidade de participar de quatro cerimônias religiosas: saída de camarinha, gira de Iemanjá, gira de Ogum e gira de Exum. Todas em diferentes datas.

No horário combinado fomos até a casa de Natalina para irmos ao terreiro. Além de nós e Natalina, foram também seu marido Nilzo e os dois netos: Ana Francisca (12 anos) e Andriano (8 anos). A cerimônia 
religiosa era uma "saída de camarinha" e estava marcada para iniciar no início da noite. Ao chegarmos ao local percebemos que aos poucos muitas pessoas foram chegando para cerimônia entre adultos e crianças. Muitos apenas para assistir, observamos o altar, as imagens dos orixás na parede e os atabaques. Natalina e a neta participaram da cerimônia no centro do terreiro com roupas especiais que levaram para serem colocadas lá. Seu marido e Andriano as assistiam. Havia pessoas que ajudavam para que tudo ocorresse de forma organizada. Estas pessoas são chamadas de

12 Cambone é a pessoa responsável por servir aos orixás e entidades incorporadas os seus objetos de uso pessoal (Pedro, 1999).

13 Informação contida no diário de campo do dia 15 de janeiro de 2016. cambone. ${ }^{11}$ Natalina nos contou que Ana Francisca é cambone, pois é sua ajudante no terreiro. Durante a cerimônia houve momentos de louvor a Oxalá! Palmas e cantos ao som dos atabaques. Percebemos que grande parte das participantes do centro do terreiro eram mulheres, elas usavam saias e dançavam descalço. Aos poucos sentimos que era uma cerimônia que celebrava o feminino, sobretudo pela referencia feita ao orixá Iemanjá, anfitriã da ancestralidade. No meio da cerimônia foi realizado um batizado de um bebê, ele é iniciado no terreiro e acolhido pelo povo de santo que celebra com rezas e cantos a iniciação. Ao final da cerimônia houve interação entre adultos e crianças e foi servido canjica para quem quisesse saborear. $^{12}$

Desse primeiro dia no terreiro com Natalina e seus familiares, chamou-nos a atenção os lugares do feminino e da criança na cerimônia religiosa. Não pudemos deixar de pensar sobre a criança e o terreiro, sobre o que os estudos de Caputo (2012) ajudaram a pensar. A autora faz um trabalho sobre as crianças e o terreiro de candomblé na região do Rio de Janeiro; recorremos a ela, pois, quando pesquisamos sobre as crianças e o terreiro de Umbanda na região de Florianópolis, não encontramos referências. A presença das crianças na cerimônia de batismo, ou seja, na iniciação, no toque dos atabaques e na circulação como cambone, além de muitas outras ali presentes acompanhando seus familiares, fizeram-nos pensar sobre o que Caputo (2012) muito bem apresentou: o aspecto da educação nos terreiros. Diríamos mais: que este está relacionado aos processos de socialização 
que envolvem a dimensão do pertencimento étnico-racial. A presença das crianças no terreiro de Umbanda desperta-nos para a importância deste espaço para a preservação da matriz africana de pensar, viver e agir no mundo. São inúmeros os símbolos e as linguagens que a criança negra e quilombola (re) encontra de sua cultura, história e etnia nestes espaços.

Na cerimônia Gira de Iemanjá, Natalina e a neta Ana Francisca participaram novamente em lugar de destaque, Natalina participa da gira e Ana Francisca é cambone. Neste dia aproveitamos para perguntar a Natalina se os(as) filhos(as) e netos(as) haviam sido batizados na umbanda. Ela contou-nos que a maioria foram batizados na referida religião. Indagamos a Natalina sobre quem podia ficar dançando no "terreiro" com as roupas brancas? Natalina nos responde: "olha, a partir da hora que a pessoa se desenvolve e começa a receber, pode". Neste dia a filha de Natalina, Beia e sua filha, Iara (2 anos) também assistiram a cerimônia. Durante a cerimônia observamos duas figuras de destaque no terreiro: a mãe de santo e Iemanjá. Ao final Natalina comenta: "para cada orixá existe um ritual, por isto nada é igual no terreiro, tudo muda". Indagada a falar sobre como início na religião umbanda, ela conta: "meu pai era umbandista. Eu vou desde criança”. Neste momento refletimos que muitas crianças frequentam terreiros e/ou igrejas com os pais e familiares. Beia aproveita para dizer: "eu sou bem franca a dizer: eu não sou da igreja, eu sou do terreiro". ${ }^{14}$

Novamente, a cerimônia religiosa no terreiro fez referência ao feminino ao chamar a presença da mãe de santo, que contribui para marcar o lugar do feminino na matriz africana: as roupas, os adereços nos cabelos, a dança, a música, os modos de rezar e girar no terreiro são expressões de uma espiritualidade afro.

Beia e sua filha Iara, de 2 anos, assistem à cerimônia, inseridas no ritual do terreiro. A mulher expressa sua preferência ao terreiro à igreja. Ao dizer-se do terreiro, ela diz de si, de seus modos de subjetivar-se no mundo; não é possível viver esse processo isoladamente, então, ela o faz junto das
14 Informação contida no diário de campo do dia 16 de janeiro de 2016. 
mulheres de sua família (sua mãe, sua filha e sua sobrinha). Ao expressar-se sobre sua religiosidade, descobrimos que ela também é cambone.

Neste dia combinamos de ir ao terreiro na cerimônia Gira de Ogum. Era uma sexta-feira e estava chovendo muito. Estávamos em Florianópolis, combinamos com Natalina de pegá-las na rodoviária localizada no centro da cidade. Por volta das $19 \mathrm{~h}$ ela nos liga dizendo que estavam chegando, além dela, Ana Francisca, Beia e Iara. Disseram que em Paulo Lopes chovia muito, mas não desistiram de vir. Natalina trazia nas mãos uma bolsa grande com as roupas para a cerimônia. Percebemos que todas estavam com tranças nos cabelos. Quando entramos no terreiro, Natalina e Ana Francisca foram trocar as roupas para participarem da gira. Nós sentamos junto daqueles que vinham para assistir a cerimônia. Quando iniciou a cerimônia havia quase 30 pessoas dançando no terreiro, entre homens e mulheres, eles usavam roupas brancas com vermelho, Natalina usava roupa branca com uma capa vermelha. Percebemos a presença de crianças que corriam pelo terreiro e ajudavam a tocar os atabaques. Percebemos o quanto o som do atabaque é fundamental na cerimônia e ao ver as crianças refletimos sobre este lugar de destaque. Ao final Natalina nos comenta que era filha dos orixás Ogum e Oxum, por isto fez de tudo para não faltar a gira de seu orixá. Perguntamos como ela sabia o seu orixá? Natalina diz que no desenvolvimento o primeiro santo que vem é o chefe de cabeça. No seu caso foi Ogum, então era filha de Ogum. Perguntamos como ela soube que era Ogum? O que aconteceu no desenvolvimento? Natalina diz: "Oh meu pai já trazia já de berço como diz o ditado, meu pai era de umbanda, meu pai era curandeiro, aliás, a família toda, as minhas tias, as minha primas, todas eram, então já tinha que ser mesmo". Aproveitamos para perguntar se as crianças tinham orixás? Ela diz que não, que "quando vão crescendo vão desenvolvendo". ${ }^{16}$

Natalina levou novamente a filha e as netas para a cerimônia religiosa, em outra data. Mesmo o tempo chuvoso não as impediu de irem de ônibus para Florianópolis. 
O deslocamento do quilombo ao terreiro é um exercício

que preserva a religiosidade destas mulheres e crianças, que buscam afirmar a matriz africana de sua religiosidade. A presença dos orixás na vida dessas mulheres e crianças revela que a fé é transversalizada pelo feminino e pelo masculino. É essa composição plural e singular de cada orixá que dá sentido à crença dessas mulheres. Após a gira de Ogum, Natalina revelou que é filha deste orixá, por isso, talvez, todo esforço realizado para ir à cerimônia e o uso da capa vermelha para dançar e do penteado nos cabelos, símbolos reveladores de seu pertencimento étnico-racial. Aproveitamos para indagar Natalina sobre a (in)existência de terreiro no espaço da Toca de Santa Cruz, sobre o que se relatou:

Estivemos na casa de Natalina e ao conversarmos sobre nossa curiosidade da existência de terreiro no espaço do quilombo ela levantou-se e nos chamou para caminhar até o terreno que estava sendo preparado para construção do seu terreiro, Iara, sua neta nos acompanhava. Disse que busca a viabilidade da construção na prefeitura, pois não quer correr riscos. Em seguida retornamos para sua casa e permanecemos na varanda, ela entrou e logo nos trouxe uma pasta com diversos papeis, fez questão de nos mostrar um por um. O primeiro deles era uma declaração da Fundação Umbanda Candomblé Angola (FUCA), era uma declaração de histórico de ordenação. Além deste documento, Natalina mostrou o alvará de funcionamento com nome dela. Outro documento dizia sobre o grau espiritual: Yalorixá, segundo ela quer dizer chefe de terreiro. Além disto, mostrou fotografias de sua participação em terreiros fora da Toca. Entre os documentos, havia o registro do nome de seu centro espírita: Cabloca Jurema com sede na rua Manoel Felipe, com número de registro e atualizado, desde 01/12/2015, ela também mostrou a carteirinha de umbandista e falou: "eu posso tocar e a policia não pode nem chegar ali e mandar parar. Eu tenho o alvará e ninguém pode me impedir. Se a polícia endoidar e quiser ir ali (no terreiro) eu vou mostrar estes documentos". ${ }^{16}$

Natalina sugeriu a importância de uma "regulamentação" da religiosidade para se proteger do policiamento. Talvez isso
16 Informação contida no diário de campo do dia 12 de janeiro de 2016. 
possa ter relação com os processos discriminatórios vividos pelos umbandistas, como apontam pesquisas como a de Tramonte (2001), a qual apresenta a trajetória histórica das religiões afro-brasileiras de Desterro à Grande Florianópolis, destacando a marcante presença da Umbanda nessa geografia. Natalina traz a polícia e o policiamento como um processo de vigilância que faz com que umbandistas precisem, em alguma medida, precaver-se, tendo em mãos tal conjunto de documentação, que serve como aporte ao direito de viver a religiosidade africana, algo que também é explorado por Tramonte (2001), que nos conscientiza sobre os processo de discriminação e de invisibilidade vivido pelo povo de santo, o qual não deixa de demarcar seu terreno através de inúmeras estratégias de resistência coletiva.

Natalina prepara o terreno do terreiro da comunidade quilombola. Ela se ocupa da documentação e da viabilidade técnica, mas também se ocupa em mostrar o terreno para sua neta, que cresce ao redor dela, ou seja, a mulher se ocupa da tradição e da ancestralidade. $O$ terreno escolhido para o terreiro fica localizado próximo a sua casa e de seus familiares - filhos(as), netos(as), bisnetos(as), noras e genros). É nessa geografia que ela vislumbra praticar sua matriz religiosa africana e fortalecer os laços de parentesco.

Para Theodoro (1996), a fé na religião é um dos apoios da mulher negra, seu axé. Sua atuação na comunidade se complementa com sua força espiritual trabalhada nas comunidades-terreiros. $\mathrm{Na}$ cultura negra, o som, a palavra são elementos mobilizadores, que conduzem à ação, que propiciam axé, o qual se desenvolve na comunidade-terreiro, que funciona como um centro irradiador de todo um sistema cultural. Pela oralidade, se fazem presentes no ritual as cantigas, os textos míticos, as histórias de "seres animais", as lendas, os acontecimentos, as músicas, as danças, etc. Esses elementos explicitam o universo cultural negro e alimentam seu sistema de conhecimento e as relações de grupo. No ritual, o orixá é invocado a responder por intermédio do transe individual do(a) participante; assim, o sujeito que fala é sempre 
imediato, concreto, pois só dessa forma se transmite o axé, indispensável à dinamização das trocas e da existência. Cada ato de comunicação é único, renascendo apenas no ritual. Por intermédio "do segredo do ritual, se ligam e se constituem os vínculos comunitários, evidenciando-se a potência do sagrado [...]"(THEODORO, 1996, p. 63).

\section{Considerações finais}

$\mathrm{Na}$ etnografia realizada na Toca, encontramos nas práticas partilhadas por mulheres e crianças no terreiro, a cosmologia que integra rituais, corporeidades, estéticas e ancestralidades próprias do quilombo. $\mathrm{O}$ que percebemos é que, nesse espaço do terreiro, as práticas de socialização atuam sob relações intra-geracionais, de modo que os processos simbolizados pela cerimônia, bem como as vestes e os adereços ali partilhados, incidem como um complexo processo social que inscreve os sujeitos que ali estão. Mulheres e crianças, em relações de mútua interdependência, atualizam a ancestralidade através de rituais nos quais o sagrado reúne a esfera conectiva da vida cotidiana com o tempo (passado, presente e futuro/além). Essa é uma cosmologia complexa que incide sobre a cotidianidade das crianças e das mulheres, pois é virtualmente compreendida como uma construção simbólica que atua sobre os modos de existência na Toca.

\section{Referências}

BOTEGA, Gisely Pereira. Desigualdades étnicas e de gênero no mercado de trabalho na perspectiva das mulheres negras da comunidade de Santa cruz do município de Paulo Lopes/SC. 2002. 75 folhas. Trabalho de conclusão de curso (Graduação em Psicologia)-Universidade do Sul de Santa Catarina, Palhoça, 2002.

As Relações Raciais nos Contextos Educativos: suas implicações na constituição do autoconceito de crianças negras moradoras da comunidade de Santa Cruz do município de Paulo Lopes/SC. 2006. 132 f. Dissertação (Mestrado em Educação)Universidade Federal de Santa Catarina, Florianópolis, 2006. 
;TRAMONTE, Cristiane.Memórias deMulheres Quilombolas: a reconstrução histórica de Santa cruz (SC). Revista Memórias Rurais e Urbanas, Chapecó, v. 28, n. 42, p. 77-86, jun. 2015.

BRASIL. Constituição da República Federativa do Brasil. Brasília, DF: Senado Federal, 1988.

. Decreto no 4887 de 20 de novembro de 2003. Regulamenta o procedimento para identificação, reconhecimento, delimitação, demarcação e titulação das terras ocupadas por remanescentes das comunidades dos quilombos de que trata o art. 68 do Ato das Disposições Constitucionais Transitórias. Diário Oficial [da] República Federativa do Brasil, Brasília, DF, 20 nov. 2003.

CAPUTO. Stela Guedes. Educação nos Terreiros: e como a escola se relaciona com as crianças do candomblé. Rio de Janeiro: Pallas, 2012.

ESTADO DE SANTA CATARINA. Prefeitura municipal de Paulo Lopes. Lei no 1319, de 03 de março de 2009. Declara de utilidade pública a Associação Comunitária Quilombolas da Toca Santa Cruz. Disponível em: < http://www.paulolopes.sc.gov.br/cms/pagina/ver/ codMapaItem/58298>. Acesso em: 20 jan. 2016.

FONSECA, Claudia. Quando cada caso não é um caso: pesquisa etnográfica e educação. Revista Brasileira de Educação, São Paulo, Anped, n. 10, p. 58-78, jan./abr. 1999.

GOOGLE. Google Earth. Rua Manoel Felipe, Paulo Lopes (SC). Disponível em: <https:/www.google.com.br/maps/ place/Paulo,+SC/@-27.9706858.-48.6896625,1715m/data=!3 $\mathrm{m} 1$ ! $1 \mathrm{e} 3$ ! $4 \mathrm{~m} 8$ ! $1 \mathrm{~m} 2$ ! $2 \mathrm{~m} 1$ ! 1 srua + manoel+felipe+paulo+lopes+sc! $3 \mathrm{~m} 4$ ! $1 \mathrm{~s} 0 \mathrm{x} 9526 \mathrm{~d} 50503 \mathrm{~d} 58 \mathrm{a} 35: 0 \times 85 \mathrm{~d} 3 \mathrm{~b} 65 \mathrm{cef} 5 \mathrm{~d} 09 \mathrm{dc} ! 8 \mathrm{~m} 2$ !3d27.9613528!4d-48.6869431> Acesso em: 10 jul. 2016.

INSTITUTO BRASILEIRO DE GEOGRAFIA E ESTATÍSTICA (IBGE). [2016]. Disponível em: <http://cidades. ibge.gov.br/xtras/perfil.php?lang=\&codmun=421230\&search $=$ san ta-catarina|paulo-lopes>. Acesso em: 20 ago. 2016.

LEITE, Ilka Boaventura. O projeto Político Quilombola: desafios, conquistas e impasses atuais. Rev. de Estudos Feministas, Florianópolis, v. 16, n. 3, p. 965-977 set./dez. 2008.

MACHADO, Manuel Venâncio. Paulo Lopes: breve histórico de uma terra e seu povo. Florianópolis: Editora Lunardelli; Assembléia Legislativa, 1993. 
MOURA, Glória. Quilombos Contemporâneos no Brasil. In: KABENGELE, Munanga. História do Negro no Brasil. Brasília: Fundação Cultural Palmares; MinC, 2004.

MUNICÍPIO DE PAULO LOPES. Paulo Lopes, [2016]. Disponível em: <http://www.paulolopes.sc.gov.br/0>. Acesso em: 20 ago. 2014.

O'DWYER, Eliane Catarino. Terras de Quilombos no Brasil: direitos territoriais em construção. Revista Arús, Campina Grande, v. 14, n. 1-2, p.43-58, jan./dez. 2008.

. Quilombos: os caminhos do reconhecimento em uma perspectiva contrastiva entre o direito e a Antropologia. Revista Fronteiras, Dourados, v. 11, n. 19, p. 165-178, jan./jun. 2009.

ORTIZ, Renato. A morte branca do feiticeiro negro. Petrópolis: Vozes, 1978.

PAULA, Elaine de. Vem brincar na rua! Entre o Quilombo e a Educação Infantil: capturando expressões, experiências e conflitos de crianças quilombolas no entremeio desses contextos. 2014. 355 f. Tese (Doutorado em Educação)-Universidade Federal de Santa Catarina, Florianópolis, 2014. Disponível em: <http://tede.ufsc.br/ teses/PEED1052-T.pdf>. Acesso em: 10 abr. 2016.

ROLNIK, Suely. Cartografia Sentimental: transformações contemporâneas do desejo. 2. ed. Porto Alegre: Sulinas; Editora da UFRGS, 2014.

TEODHORO, Helena. Mito e Espiritualidade: mulheres negras. Rio de Janeiro: Pallas, 1996.

TRAMONTE, Cristiana. Educação Quilombola: temas e desafios brasileiros. In: WEBER, Catia. Educação para Populações Específicas IN: Educação para Diversidade e Cidadania. Florianópolis: MOVER/NUP/CED/EAD/UFSC, 2009.

Com a Bandeira de Oxalá! Trajetórias, práticas e concepções das religiões afro-brasileiras na grande. Florianópolis; Itajaí: Univali, 2001.

Submetido em: 18/11/2016

Aprovado em: 14/12/2016 
118 Revista Grifos

\title{
SOCIALIZATION PROCESSES IN QUILOMBO TOCA DE SANTA CRUZ IN THE CITY OF PAULO LOPES/ SC: "I'M NOT THE CHURCH, I AM TERREIRO”.
}

\begin{abstract}
This article presents part of a doctoral research in Education still ongoing and aims to understand and present processes of socialization among women and children living in the quilombo Toca de Santa Cruz in the city of Paulo Lopes / SC within and outside the quilombo. In addition, we sought to give visibility to the recognition of such territory as quilombo from ethnopolitical aspects. Data were collected from an ethnographic approach and in this text, we present field diary records produced from the religious ceremonies in a Umbanda yard in the quilombo territory. The data show that socialization processes potecializam life and modes of resistance to oppression, violence, money laundering, racism and invisibility of the subjects at the Burrow.
\end{abstract}

Keywords: Quilombo. Socialization processes. Yard. 